\title{
RENDIMIENTO DIAGNÓSTICO DE LA PRUEBA DE INMUNOFLUORESCENCIA INDIRECTA PARA LA DETECCIÓN DE ANTICUERPOS CONTRA HTLV-1
}

\author{
Soledad Romero-Ruiz ${ }^{1, a, d}$, Eduardo Miranda-Ulloa ${ }^{1, b, e}$, Ronal Briceño-Espinoza ${ }^{1, c}$
}

\begin{abstract}
RESUMEN
El objetivo del estudio fue determinar el rendimiento diagnóstico de la prueba de inmunofluorescencia indirecta (IFI) para la detección de anticuerpos contra HTLV-1. Se realizó un estudio de evaluación de prueba diagnóstica. Se usaron cultivos celulares MT2 infectados con HTLV-1 y K-562 sin infección, luego fueron sembrados, fijados en láminas para inmunofluorescencia y enfrentados a sueros. Se usaron 155 sueros (80 positivos para HTLV-1 y 75 positivos para otras enfermedades) procedentes de la seroteca del Instituto Nacional de Salud del Perú. Adicionalmente, se evaluó la repetibilidad (en el laboratorio) y reproducibilidad (en laboratorios de costa, sierra y selva) de la prueba. La prueba IFI para la detección de anticuerpos contra HTLV-1 tuvo una sensibilidad de 98,75\% (IC 95\%: 95,69-100\%), una especificidad de 98,67\% (IC 95\%: $95,40-100 \%$ ) y el índice de kappa de 0,975 . No hubo falsos positivos ni falsos negativos; sin embargo, sí se obtuvo un resultado indeterminado y uno inespecífico. La prueba mostró $100 \%$ de concordancia en la repetibilidad y reproductibilidad. Concluimos que los resultados obtenidos son comparables a la prueba de referencia. La prueba de IFI presenta un buen rendimiento diagnóstico y sería de utilidad para la confirmación de HTLV-1.
\end{abstract}

Palabras clave: Virus 1 linfotrópico Thumano; Diagnóstico, Técnica del anticuerpo fluorescente indirecta, (fuente: DeCS BIREME)

\section{DIAGNOSTIC PERFORMANCE OF THE INDIRECT IMMUNOFLUORESCENCE TEST FOR THE DETECTION OF ANTIBODIES AGAINST HTLV-1}

\begin{abstract}
The objective of the study was to determine the diagnostic yield of the indirect immunofluorescence (IFI) test for the detection of antibodies against HTLV-1. A diagnostic test evaluation study was performed. HTLV-1-infected MT2 cells and HTLV-1-uninfected K-562 cells were cultured; then these cells were impregnated and fixed in sheets for immunofluorescence and faced to Peruvian sera. A total of 155 sera (80 HTLV-1-positive sera and 75 sera positive for other diseases) from the Peruvian Instituto Nacional de Salud were used. In addition, the parameters of repeatability (intra-laboratory) and reproducibility (in laboratories of the Peruvian coast, mountains and jungle) of the test were evaluated. The IFI test detected the presence of antibodies against HTLV-1 reaching a sensitivity of $98.75 \%(95 \% \mathrm{Cl}$ : $95.69-100.00 \%)$, a specificity of $98.67 \%(95 \% \mathrm{Cl}: 95.40-100.00 \%)$ and the Kappa index was 0.975 . There were no false positives or false negatives; however, one undetermined result and one non-specific result were obtained. The test showed $100 \%$ qualitative agreement when performing the repeatability and reproducibility. The results obtained are comparable to the reference test. Therefore, the IFI test had a good diagnostic performance and would be useful for the confirmation of HTLV-1.
\end{abstract}

Key words: Human T-lymphotropic virus 1; Diagnosis, Fluorescent antibody technique, indirect, (source: DeCS BIREME)

\section{INTRODUCCIÓN}

A nivel mundial, el Caribe, Japón y algunos países de Sudamérica (entre ellos el Perú) y África son endémicos de HTLV-1; en el Perú, un estudio sistemático que incluyó estudios epidemiológicos publicados entre 1988 y $2010^{(1)}$ y una revisión realizada en el $2011^{(2)}$ reportaron que para ciertas poblaciones (trabajadoras sexuales, hombres que tienen sexo con hombres, varones $\mathrm{VIH}$ positivos y usuarios de drogas no endovenosas) las prevalencias de infección por HTLV-1 fluctuaron entre el 2 y $25 \%$.

\footnotetext{
Laboratorio de Referencia Nacional Virus de Transmisión Sexual VIH/SIDA, Centro Nacional de Salud Pública, Instituto Nacional de Salud. Lima, Perú. Biólogo microbiólogo, ${ }^{\mathrm{b}}$ biólogo, ${ }^{\mathrm{c}}$ bachiller en Tecnología Médica, ${ }^{\mathrm{d}}$ doctora en Ciencias Biológicas, ${ }^{\mathrm{e}}$ magíster en Microbiología. Recibido: 17/01/2017 Aprobado: 12/07/2017 En línea: 29/09/2017
} 
Se han reportado prevalencias de infección por HTLV-1 de hasta $2,3 \%$ en gestantes asintomáticas procedentes de los departamentos de Lima, Ayacucho y Cusco ${ }^{(1,3,4)}$; estos reportes ganan importancia ya que un estudio realizado en Lima durante el año 2007 encontró en hijos de madres seropositivas a HTLV-1, 52 casos confirmados de una población de 279 madres infectadas ${ }^{(1)}$.

En el año 2016 las frecuencias más elevadas de HTLV-1, mostradas por el Instituto Nacional de Salud (INS) del Perú, según departamentos correspondieron a Lima (32\%), Cusco (4,5\%), Arequipa (3.9\%), Apurímac (2,8\%) y La Libertad $(2,6 \%)^{(5)}$.

La detección de HfTLV-1 en los bancos de sangre del Perú se realiza con más frecuencia mediante la prueba de ELISA; los reportes de diferentes marcas comerciales muestran una sensibilidad mayor a 99,7\% y una especificidad entre 97 y $99,97 \%{ }^{(6,7)}$; otra prueba usada es la quimioluminiscencia, que alcanza una sensibilidad del $100 \%$ y una especificidad superior al $99,5 \%{ }^{(8)}$. A pesar de que ambas pruebas tienen una buena especificidad, todavía existe la posibilidad de que se presenten falsos positivos.

La prueba de inmunofluorescencia indirecta (IFI) usada en otros países endémicos de HTLV-1 es considerada confirmatoria, teniendo ventaja sobre las de tamizaje debido a que incluye en su metodología un control de especificidad ${ }^{(9,10)}$. En nuestro país, el diagnóstico confirmatorio se realiza mediante el uso de kits comerciales importados de Inmunoblot (11,12) y Western Blot (12,13); sin embargo, su costo elevado genera dificultades al momento del diagnóstico. Ante esto, países como Argentina ${ }^{(9)}$ y Chile ${ }^{(10)}$ han desarrollado kits in house de bajo costo, como la prueba de IFI para el diagnóstico confirmatorio de HTLV1 , reportando una sensibilidad igual o mayor a $97,91 \%$ y una especificidad del $100 \%{ }^{(9,10)}$.

El objetivo del presente estudio fue determinar el rendimiento diagnóstico de la prueba de IFI para la detección de anticuerpos contra HTLV-1.

\section{EL ESTUDIO}

\section{DISEÑO DEL ESTUDIO}

Estudio observacional prospectivo de evaluación de una prueba diagnóstica realizado durante los años 2014-2015. La investigación se desarrolló en cuatro etapas: selección de sueros humanos, preparación de cultivos celulares y elaboración de láminas impregnadas, técnica de IFI y evaluación del rendimiento diagnóstico.

\section{SUEROS HUMANOS EMPLEADOS}

Todas las muestras, seleccionadas por conveniencia, fueron proporcionadas por la seroteca del Laboratorio

\section{MENSAJES CLAVE}

Motivación para realizar el estudio. En Latinoamérica, se han desarrollado kits de inmunofluorescencia indirecta (IFI) in house de bajo costo para la confirmación de HTLV-1. Es necesario disponer de ésta prueba en nuestro país, ya que es endémico a este retrovirus.

Principales hallazgos. La prueba IFI alcanzó una sensibilidad del 98,75\% (IC 95\%: 95,69-100\%) y una especificidad de 98,67\% (IC 95\%: 95,40-100\%). No se reportaron falsos positivos ni falsos negativos. Hubo una adecuada repetibilidady reproducibilidad.

Implicancias. La prueba de IFI sirvió para la confirmación de HTLV1 de similar forma que el kit comercial de Inmunoblot. La prueba de IFI es de bajo costo y serviría para la vigilancia epidemiológica.

de Referencia Nacional de VTS-VIH/SIDA del INS. Se seleccionaron muestras procedentes del año 2014, las cuales se encontraban congeladas $\mathrm{a}-70^{\circ} \mathrm{C}$

Se propuso evaluar 160 sueros que fueron distribuidos en dos paneles A y B (Figura 1). El tamaño muestral fue definido por conveniencia de acuerdo a la disponibilidad de sueros en la seroteca.

Panel A. 80 sueros positivos a HTLV-1, confirmados y diferenciados por Inmunoblot comercial (INNO-LIA ${ }^{\text {TM* }}$ HTLV I/II Score; Innogenetics N. V., Gante, Bélgica) que presenta una sensibilidad de $100 \%$ y especificidad de $99 \%{ }^{(11)}$ (prueba gold standard o de referencia). Estos sueros seleccionados fueron VIH negativos, descartados por Inmunoblot (INNO-

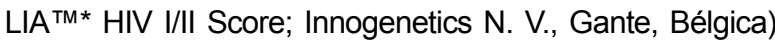
que tiene una sensibilidad de $100 \%$ y una especificidad de $96,7 \%{ }^{(14)}$. Ambas pruebas se realizaron en el INS.

Panel B. 80 sueros negativos a HTLV-1, evaluados mediante la prueba gold estándar correspondiente: 25 sueros procedieron de personas sanas y 55 procedieron de personas con las siguientes características: diez con sífilis, diez de gestantes, diez con enfermedad reumatoide, diez con hepatitis B, diez con VIH y cinco con HTLV-2.

Las muestras con sífilis fueron identificadas por FTA-ABS, los de enfermedad reumatoide por factor reumatoide $y$ proteína $\mathrm{C}$ reactiva, los de hepatitis $\mathrm{B}$ por ELISA (HBsAg), los de VIH por IFI y ELISA, las gestantes por análisis ecográfico, y los casos de HTLV-2 por Imunoblot comercial (INNO-LIA ${ }^{\text {TM* }}$ HTLV I/II Score).

\section{PREPARACIÓN DE LOS CULTIVOS CELULARES Y ELABORACIÓN DE LÁMINAS IMPREGNADAS ${ }^{(15-17)}$}

Se cultivó la línea celular MT2, células $\mathrm{T}$ humanas transformadas por cocultivos con linfocitos de leucemia crónicamente infectadas con HTLV-1. También se cultivó 


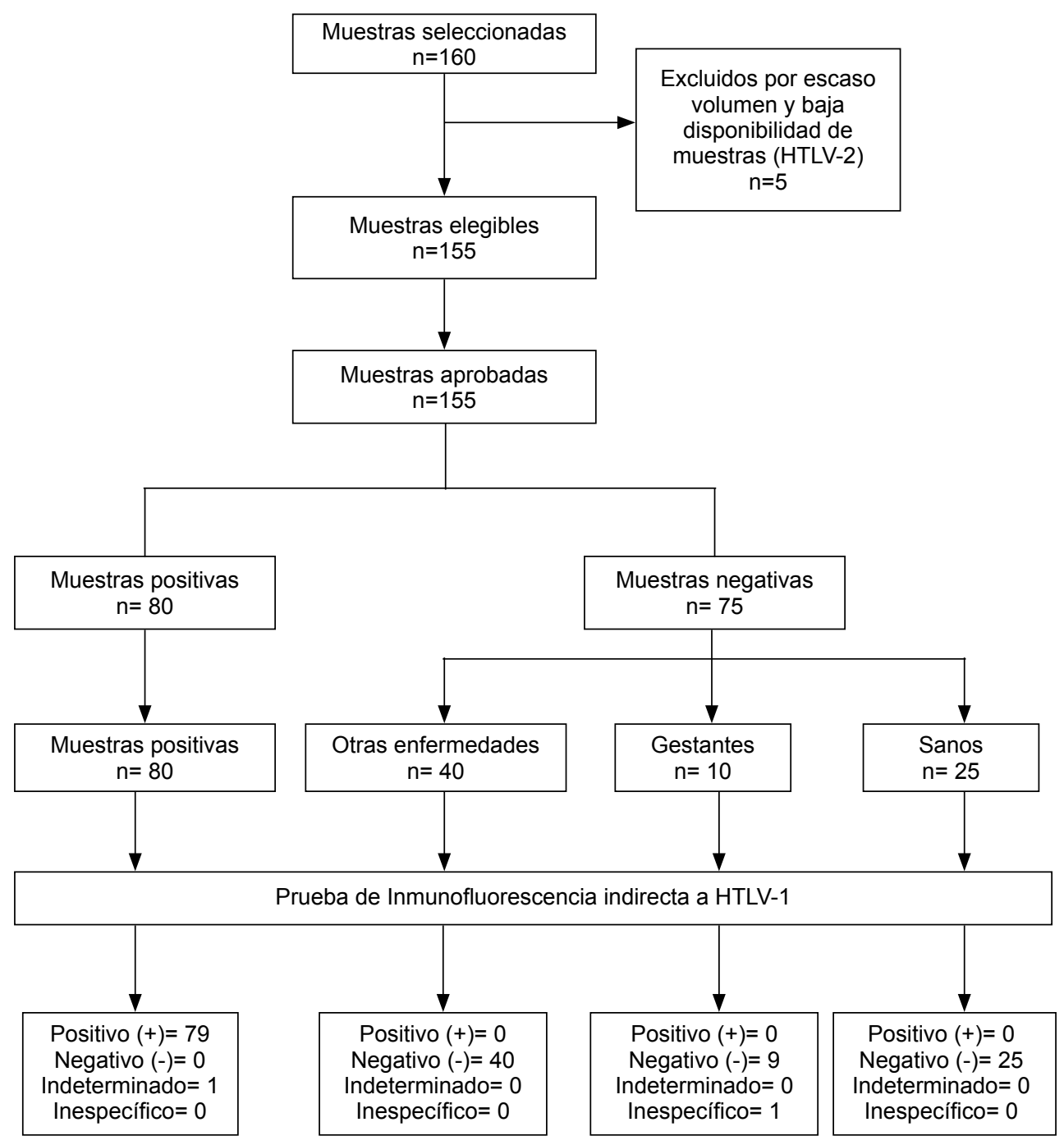

Figura 1. Diagrama de flujo de muestras incorporadas al estudio

la línea celular K-562 macrófagos humanos, la cual fue usada como células de control, no infectadas.

Las células infectadas y no infectadas con HTLV-1 fueron cultivadas por separado en frascos de $25 \mathrm{~cm}^{2}$, conteniendo medio de cultivo RPMI 90\% suplementado con suero fetal bovino al $10 \%, 100 \mathrm{uL}$ de glutamina y $100 \mathrm{uL}$ de HEPES. Las células fueron incubadas en una estufa de $\mathrm{CO}_{2}$ al $5 \%$ y a $37^{\circ} \mathrm{C}$, por cuatro a cinco días.

La suspensión celular obtenida de los cultivos fue diluida con azul de tripán para realizar el recuento celular en cámara de Newbauer; considerándose una viabilidad celular de $90 \%$.

Se utilizaron láminas de 12 pocillos de $5 \mathrm{~mm}$ (seis superiores y seis inferiores) con fondo de teflón. Para los pocillos superiores se preparó una mezcla de células no infectadas e infectadas en proporción de tres a uno respectivamente y para los pocillos inferiores se preparó suspensión de células no infectadas. En cada pocillo se agregó 20 uL de suspensión celular considerando una concentración de 6000 a 8000 células por pocillo. Las láminas se dejaron secar a temperatura ambiente y se fijaron en acetona fría por $10 \mathrm{~min}$, luego se secaron y se conservaron a $-20^{\circ} \mathrm{C}$.

\section{TÉCNICA DE INMUNOFLUORESCENCIA INDIRECTA}

Principio de la prueba de IFI. Los anticuerpos contra HTLV1 se unen al antígeno viral que está en las células adheridas al portaobjeto. Este complejo es detectado mediante la adición de anti-lgG humana conjugada con isotiocianato de fluoresceina. Posteriormente, la reacción es observada mediante un microscopio de epifluorescencia.

Titulación del conjugado. Se usó anti-lgG humano conjugado con isotiocianato de fluoresceína de marca Capell (Capell Lab., Cochranville, PA, USA) por sus 
especificaciones técnicas de conservación (entre 2 y $8^{\circ} \mathrm{C}$ ); esta condición al momento de su uso la hace adaptable a las diferentes regiones del Perú. El conjugado fue titulado y evaluado usando positivos fuertes (aquellos sueros que en la prueba de referencia mostraron todas las bandas específicas con una intensidad de tres cruces).

Los sueros positivos fuertes fueron procesados cada uno por quintuplicado a la dilución 1/10; luego se incubó el conjugado realizando una titulación de 5 diluciones: $1 / 20$, $1 / 40,1 / 80,1 / 160$ y 1/320. Se escogió la dilución 1/160 como la dilución óptima para su uso, debido a que esta fue la más alta dilución que reveló una fluorescencia brillante en los sueros positivos fuertes procesados.

Prueba de IFI. Se diluyó los sueros control positivo y negativo 1/10 con Buffer fosfato salino (PBS) pH 7,2. Además, se usó un control PBS que sirvió para validar el ensayo. Luego se colocó 20 uL de los sueros diluidos en cada uno de los pocillos superiores e inferiores y se incubó los portaobjetos en una cámara húmeda a $37^{\circ} \mathrm{C}$ durante $30 \mathrm{~min}$. Se enjuagó las láminas en PBS, dos veces durante cinco minutos por vez, en agitación constante y se dejó secar a temperatura ambiente.

El conjugado se diluyó $1 / 160$ con PBS, a esta mezcla se añadió azul de Evans 100X (1X dilución final) y se agregó 20 uL a cada pocillo superior e inferior. Se incubó en cámara húmeda a $37^{\circ} \mathrm{C}$ durante $30 \mathrm{~min}$. Se lavó las láminas con PBS, dos veces por cinco minutos cada vez, y se enjuagó con agua destilada; finalmente se agregó el medio de montaje glicerinado y la laminilla cubreobjetos.

Interpretación de resultados. Positivo: se consideró positivo a anticuerpos contra HTLV-1 cuando se visualizó fluorescencia en el pocillo superior; el resultado fue válido si en el pocillo inferior no se visualizó fluorescencia. Negativo: se consideró negativo a anticuerpos contra HTLV-1 cuando no se visualizó fluorescencia en el pocillo superior; el resultado fue válido si en el pocillo inferior no se visualizó fluorescencia. Inespecífico: cuando se visualizó fluorescencia en el pocillo superior y también en el pocillo inferior. Indeterminado: cuando no se visualizó una fluorescencia clara en el pocillo superior, a pesar que en el pocillo inferior indique no fluorescencia.

\section{ANÁLISIS ESTADÍSTICO}

Se elaboró una tabla de contingencia de dos por dos para el cálculo de la sensibilidad, especificidad, valores predictivos, razones de verosimilitud (LR), índice de validez, índice de Youden e índice de Kappa considerando un nivel de confianza de 95\% (IC 95\%). El análisis estadístico se realizó utilizando el programa Epidat v3.1 y Excel.

Para determinar la sensibilidad y la especificidad se usó el total del panel A y el panel B. Los resultados fueron leídos por tres analistas y a ciegas. El resultado final se obtuvo cuando al menos dos observadores coincidían en su lectura.

Para determinar la repetibilidad de los resultados se evaluaron ocho muestras del panel A y ocho del panel B. Estas muestras fueron procesadas y repetidas tres veces en tres días sucesivos por un mismo analista.

Para determinar la reproducibilidad del kit se usaron 48 sueros, de los cuales 24 fueron del panel A y 24 del panel B. Los lugares donde se evaluó la reproducibilidad fueron en los Laboratorios de referencia regional (LRR) de: La Libertad, Huánuco, Junín, Madre de Dios y Loreto. Durante el procesamiento en cada laboratorio se registró la temperatura ambiental; además, se usaron los equipos (estufa, agitador, microscopio de epifluorescencia y micropipetas) pertenecientes a cada laboratorio. Del mismo modo las lecturas fueron leídas a ciegas y por dos analistas del mismo equipo investigador.

Los LRR fueron seleccionados con la finalidad de representar y evaluar los factores que podrían influir en los resultados, dada la diversidad climatológica medioambiental que existe entre la costa, la sierra y la selva. Para medir la concordancia cualitativa de la repetibilidad y reproducibilidad, se utilizaron porcentajes.

Las temperaturas ambientales registradas durante la evaluación de la reproducibilidad fueron: LRR La Libertad $\left(20-23^{\circ} \mathrm{C}\right)$, LRR Junín $\left(16-19^{\circ} \mathrm{C}\right)$, LRR Huánuco $\left(20-23^{\circ} \mathrm{C}\right)$, LRR Madre de Dios $\left(27-30^{\circ} \mathrm{C}\right)$, LRR Loreto $\left(25-28^{\circ} \mathrm{C}\right)$.

\section{ASPECTOS ÉTICOS}

El protocolo del estudio fue aprobado por el Comité de Investigación y el Comité de Ética del INS (código: OI-023-14).

\section{RESULTADOS}

Del total de 160 muestras propuestas, solo se consideraron 155 debido a que la seroteca no disponía de muestras adecuadas con HTLV-2. De las 155 muestras restantes, 80 fueron asignadas al panel A (muestras positivas para HTLV-1) y 75 al panel $B$ (muestras negativas para HTLV-1). (Figura 1).

La tabla 1 detalla los resultados de las pruebas de inmunoblot e IFI para la detección de HTLV-1 en suero. Respecto al IFI, en el panel A (positivo) se tuvo una muestra indeterminada y no hubo falsos negativos; en el panel B (negativos) se obtuvo un resultado inespecífico, procedente de una gestante, además no se encontraron falsos positivos en los sueros de personas con patologías diferentes al HTLV-1. 
Tabla 1. Ensayos comparativos entre la prueba de Inmunoblot e IFI.

\begin{tabular}{lccc}
\hline \multirow{2}{*}{ Prueba IFI } & \multicolumn{2}{c}{ Prueba Inmunoblot } & \multirow{2}{*}{ Total } \\
\cline { 2 - 3 } & Positivo & Negativo & \\
\hline Positivo & 79 & 0 & 79 \\
Negativo & 0 & 74 & 74 \\
Inespecífico & 0 & 1 & 1 \\
Indeterminado & 1 & 0 & 1 \\
Total & 80 & 75 & 155 \\
\hline
\end{tabular}

IFI: inmunofluorescencia indirecta

La sensibilidad de la prueba de IFI para detectar anticuerpos contra HTLV-1 fue de 98,75\% (IC 95\%: 95,69-100\%), la especificidad de 98,67\% (IC 95\%: 95,40-100\%). El índice de Youden de 0,97 confirma el hecho de que la posibilidad de tener falsos positivos o negativos es pequeña; de similar manera, una razón de verosimilitud negativa pequeña $(0,01)$ es coherente con los demás resultados. Los demás indicadores de precisión diagnóstica se encuentran en la Tabla 2.

El índice de Kappa obtenido intralaboratorio fue de 0,975. La repetibilidad evaluada intralaboratorio tuvo una concordancia cualitativa del $100 \%$ y la reproducibilidad evaluada en costa, sierra y selva presentó una concordancia del $100 \%$.

La lectura válida para la positividad y negatividad a HTLV1 se muestra en la Figura 2.

\section{DISCUSIÓN}

Estudios realizados en Argentina demostraron la utilidad de la prueba de IFI in house para la confirmación de la infección por HTLV-1 por ser muy sensible, específica y de rápida realización ${ }^{(16,17)}$. Nuestra experiencia muestra que la prueba de IFI para la confirmación de HTLV-1 implementada en Perú presenta un alto redimiento diagnóstico.

El estudio desarrollado por Balangero en el año 2007 encontró, para el kit IFI-HTLV-1, una sensibilidad de

Tabla2. Características delapruebadeinmunofluorescencia indirecta para la detección de anticuerpos contra HTLV-1

\begin{tabular}{lr}
\hline Prueba diagnóstica & \multicolumn{1}{c}{ Valor (IC 95\%) } \\
\hline Sensibilidad (\%) & $98,75(95,69-100,00)$ \\
Especificidad (\%) & $98,67(95,40-100,00)$ \\
Índice de validez (\%) & $98,71(96,61-100,00)$ \\
Valor predictivo positivo (\%) & $98,75(95,69-100,00)$ \\
Valor predictivo negativo (\%) & $98,67(95,40-100,00)$ \\
Índice de Youden & $0,97(0,94-1,01)$ \\
Razón de verosimilitud negativa & $0,01(0,00-0,09)$ \\
\hline
\end{tabular}

IC 95\%: Intervalo de confianza al 95\%

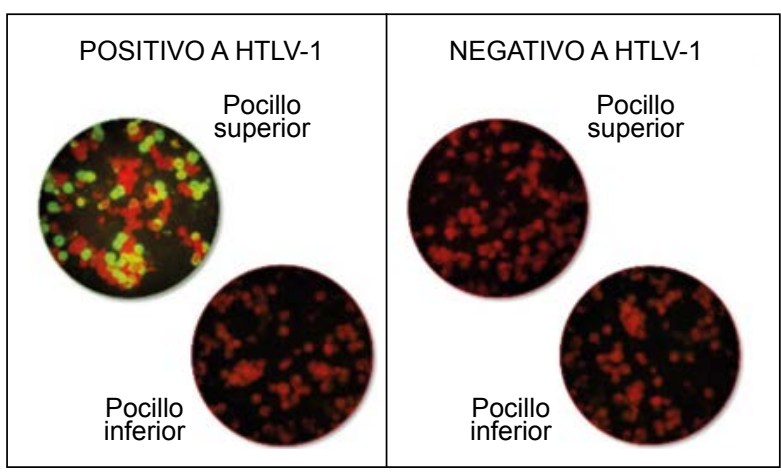

Fotografía propiedad de los autores.

Figura 2. Lectura de la prueba de inmunofluorescencia indirecta: positivo a HTLV-1 (células con fluorescencia en el pocillo superior); Negativo a HTLV-1 (células sin fluorescencia en el pocillo superior).

$97,91 \%$, una especificidad de $100 \%$ y un índice de kappa de 0,98 , atribuyendo la alta especificidad del ensayo al uso de un control de células no infectadas ${ }^{(16)}$. Nuestros resultados, para los mismos indicadores, son similares; además, en cuanto a especificidad no obtuvimos ningún falso positivo con los sueros de personas con sífilis, VIH, hepatitis $B$, enfermedad reumatoide, gestantes y sanas, lo cual califica a nuestra prueba como confirmatoria para HTLV-1.

Hemos demostrado en este estudio que la prueba de IFI-HTLV-1 mostró sensibilidad, especificidad e índice de Kappa comparable a la prueba de referencia de Inmunoblot (11).

El programa de control externo de la calidad en serología desarrollado en América Latina y dirigido por el Hemocentro de Sao Paulo en el año 1999, para los países participantes con la prueba IFI-HTLV-1, no encontró ningún falso positivo ni falso negativo; sin embargo, en el control realizado en el año 2000 sí hubo falsos positivos y falsos negativos, atribuyéndose ese efecto a una falta de experiencia por parte de las instituciones que realizaban las pruebas ${ }^{(18)}$. Destaca, entonces, la experiencia del analista al momento del análisis pues la lectura de resultados es visual y consecuentemente está sujeta a un mayor riesgo de cometer errores.

En Chile, la confirmación del diagnóstico de la infección con HTLV es realizada desde el año 2009 por el Instituto de Salud Pública, empleando la prueba de IFI (10). Esto demuestra la gran importancia diagnóstica como prueba de referencia internacional.

En Cuba, la prueba de IFI también es usada para la detección de antígenos virales (en células y tejidos), lo cual es de bastante utilidad como técnica confirmatoria para establecer la positividad del cultivo a HTLV-1 ${ }^{(19)}$. 
El rango de temperaturas registradas en el momento del procesamiento de las muestras en costa, sierra y selva estuvo entre 16 y $30^{\circ} \mathrm{C}$; obteniéndose $100 \%$ de concordancia cualitativa por al menos dos analistas. Estos resultados nos indican que la prueba de IFI-HTLV-1 puede reproducirse e implementarse en cualquier laboratorio del Perú sin ningún tipo de inconvenientes. Sin embargo, en los departamentos que presenten alta humedad ambiental recomendamos ventilación en el laboratorio para disminuir el tiempo de espera en el secado de las láminas.

En el Perú, todavía no se han establecido políticas ni estrategias para la prevención y control del virus HTLV1 y hasta la actualidad el Ministerio de Salud todavía no ha desarrollado una norma técnica que involucre el diagnóstico y el manejo del paciente con HTLV-1, como sí sucede en Brasil ${ }^{(20,21)}$. Con esta tecnología desarrollada in house, de bajo costo y de buen rendimiento diagnóstico, pretendemos aportar en el desarrollo de una norma técnica e incluir en el algoritmo de diagnóstico serológico a la prueba de IFI- HTLV -1.

Una de las limitaciones que podemos señalar es que en el Perú no hay reportes de evaluación sobre la reactividad de kits comerciales de Inmunoblot y Western Blot para la confirmación de HTLV, es por esa razón que decidimos tomar como Gold Estándar el Inmunoblot de la marca Innogenetics debido a que en sus insertos reporta alta sensibilidad y especificidad ${ }^{(11)}$ y además es la que se usa para confirmación en los laboratorios de referencia en el Perú.

Los resultados de la presente investigación nos podrían permitir incorporar a IFI como una prueba alternativa para la confirmación diagnóstica de infección por el HTLV-1 quedando los kits comerciales de Inmunoblot (11) y Western Blot ${ }^{(13)}$ para ser usados en los casos en los que IFI resulte inespecífico o indeterminado.

Los resultados de los parámetros obtenidos en la prueba de IFI-HTLV-1 la califican como una prueba de buen rendimiento diagnóstico y la hace útil para la confirmación serológica, En consecuencia, recomendamos que debiera tenerse en cuenta su uso en el Perú.

\begin{abstract}
Contribuciones de autoría: RBE realizó la selección y aporte de las muestras de suero, procesamiento. SRR realizó la preparación del cultivo celular y láminas IFI. SRR y EMU realizaron la lectura de los resultados y el análisis e interpretación de los datos. Todos los autores participaron en la evaluación de repetibilidad, EMU y RBE en la de reproductibilidad. EMU participó en la concepción, diseño y redacción del artículo. Todos los autores aprobaron la versión final del artículo.
\end{abstract}

Agradecimientos: a la bióloga Estela Huamán Ángeles (INS), por el apoyo en la caracterización de los sueros y procesamiento, a la bióloga Bernardina Amorín Uscata (INS) por el apoyo administrativo en el proyecto, al personal de los laboratorios de La Libertad, Junín, Huánuco, Loreto y Madre de Dios, a los biólogos Omar Orellana Díaz, Percy Asmat Marrufo y Margarita Zuñiga Saca por el apoyo en la evaluación de la reproducibilidad. A la Tec. Lab. Benedicta Yana Calatayud (INS) por el apoyo en la evaluación de la repetibilidad y reproducibilidad.

Fuentes de financiamiento: el proyecto fue financiado por el INS en el marco del Fondo Concursable 2014, organizado por el Centro Nacional de Salud Pública.

Declaración de conflictos de interés: los autores declaran no tener conflictos de interés en la publicación de este artículo.

\section{REFERENCIAS BIBLIOGRÁFICAS}

1. Romaní F. Revisión sistemática de estudios epidemiológicos sobre la infección por el virus linfotrópico de células $\mathrm{T}$ humanas I/II en el Perú. Rev Peru Epidemiol. 2010;14(3):[aprox. 9 p.].

2. Alarcón J, Romaní $F$, Montano S, Zunt JR. Transmisión vertical de HTLV-1 en el Perú. Rev Peru Med Exp Salud Publica. 2011;28(1):101-8. doi: 10.1590/S172646342011000100016

3. Falconi-Falconí P, Moncada-Vilela Z, Montero-Navarrete $S$, Hernandez-García J. Reporte de un caso de estrongiloidiasis con coinfección por HTLV-1 y onicomicosis. Rev Gastroenterol Perú. 2013;33(4):348-51.

4. Ita F, Mayer EF, Verdonck K, Gonzalez E, Clark D, Gotuzzo E. Human T-lymphotropic virus type 1 infection is frequent in rural communities of the southern Andes of Peru. Int J Infect Dis. 2014;19(2):46-52. doi: 10.1016/j. ijid.2013.10.005

5. Instituto Nacional de Salud (INS). Anuario Estadístico 2016. Lima, Perú: Ministerio de Salud, INS; 2017 [citado el 15 de marzo 2017]. Disponible en: http:// www.ins.gob.pe/insvirtual/images/ otrpubs/pdf/Anuario_2016.pdf

6. Biokit. Bioelisa HTLV-I+II 5.0 Product improvement [Internet]. Barcelona, España: BIOKIT, S.A.; 2010 [citado el 15 de marzo 2017]. Disponible en: http:// www.biokit.com/ /media/biokit/doc/ news/n_3621152010119_pdf.pdf

7. MP diagnostics. ELISA HTLV I/ II 3.0 [Internet]. Ginebra, Suiza: MP Biomedicals Suisse S.A.; 2005 [citado el
15 de marzo 2017]. Disponible en: http:// www.biodiagnostico.com.ar/files/206.pdf

8. DiaSorin. LIAISON XL MUREX recHTLV-I/II (REF 310270) [Internet]. Saluggia, Italia: DiaSorin S.p.A.; 2012 [citado el 15 de marzo 2017]. Disponible en: http://www.annardx.com/productos/ images/productos/diagnostica/ infecciosas/liaison-xl-murex-rec-htlv-iii-310270.pdf

9. Moreno C, Balangero M, Barbás MG, Cudolá $\mathrm{A}$, Gallego $\mathrm{S}$. Diagnóstico serológico de HTLV-1/2: combinación de técnicas de tamizaje para definir el estatus serológico en donantes de sangre. Rev Argent Microbiol. 2013;45(3):165-8.

10. Instituto de Salud Pública de Chile. Virus linfotrópico de células $\mathrm{T}$ humano tipos I y II (HTLV-I/II). Chile, 2010-2014. 
Boletín Instituto de Salud Pública de Chile [Internet]. 2015 [citado el 15 de marzo 2017];5(8):[aprox. 7 p.]. Disponible en: http://www.ispch.cl/sites/default/files/ BOLETIN\%20HTLV.pdf

11. INNOGENETICS. INNO-LIA ${ }^{\text {tw }}$ HTLV I/II Score [Internet]. Gante, Bélgica: INNOGENETICS.N.V.; 2011 [citado el 15 de marzo 2017]. Disponible en: http://www.bio-protech.com.tw/ databank/DataSheet/PathoDiag/ Innogenetics/user's\%20manual/80540 HIV_Score_110704.pdf

12. Umeki K, Umekita K, Hashikura Y, Yamamoto I, Kubo K, Nagamoto Y, et al. Evaluation of line immunoassay to detect HTLV-1 infection in an endemic area, Southwestern Japan; Comparison with Polymerase Chain Reaction and Western Blot. Clin Lab. 2017;63(2):227-33. doi: 10.7754/Clin.Lab.2016.160501

13. MP Diagnostics. HTLV BLOT 2.4 Western blot assay [Internet]. Singapur: MP Biomedicals Asia Pacific Pte. Ltd. ; 2010 [citado el 15 de marzo 2017]. Disponible en: http://www.fda.gov/downloads/ BiologicsBloodVaccines/BloodBloodProducts/ApprovedProducts/LicensedProductsBLAs/BloodDonorScreening/ InfectiousDisease/UCM426615.pdf

14. INNOGENETICS. INNO-LIA ${ }^{\text {m* }} \mathrm{HIV} \mathrm{I/}$ II Score [Internet]. Gante, Bélgica: INNOGENETICS.N.V.; 2006 [citado el 15 de marzo 2017]. Disponible en: http://search. cosmobio.co.jp/cosmo_search_p/search_ gate2/docs/IGT_/80540.20070926.pdf

15. Valverde A, Romero S. Manual de procedimientos para el diagnóstico del virus de la inmunodeficiencia humana tipo 1 (VIH 1) por inmunofluorescencia indirecta. Serie de Normas Técnicas $N^{\circ} 29$ [Internet]. Lima, Perú: Instituto Nacional de Salud; 2001 [citado el 15 de marzo 2017]. Disponible en: http://www.bvs. ins.gob.pe/insprint/salud_publica/nor_ tec/29.pdf

16. Gastaldello R, Gallego S, Isa MB, Nates $S$, Medeot $S$. Efficiency of indirect immunofluorescence assay as a confirmatory test for the diagnosis of human retrovirus infection (HIV-1 and HTLV-I/II) in different at risk populations. Rev Inst Med trop S Paulo. 1999;41(3):159-64. doi: 10.1590/S0036-46651999000300005

17. Balangero M, Bárbas MG, Berini C, Gastaldello R, Biglione M, Gallego S. Problemática del diagnóstico de la infección por retrovirus humanos (HTLV-1/2) productores de leucemias/linfomas $\mathrm{T} y$ síndromes neurológicos degenerativos. Propuesta de un algoritmo alternativo. Experiencia Médica. 2008;26(1):7-13.

18. Sáez-Alquezar A, Otani MM, Sabino EC, Salles NA, Chamone DF. Programas de control externo de la calidad en serología desarrollados en América
Latina con el apoyo de la OPS entre 1997 y 2000. Rev Panam Salud Pública. 2003;13(2-3):91-102. doi: 10.1590/ S1020-49892003000200009

19. Navea L, Dubed M, Álvarez G, Blanco M, Díaz F, Beguerías R, et al. Aislamiento del virus linfotrópico de células $T$ humano tipo I de un paciente con paraparesia espástica tropical: primer reporte en Cuba. Rev Cubana Med Trop. 2008;60(2):190-6.

20. Ministério da Saúde. Guia de manejo clínico da infecção pelo HTLV [Internet, Portugués]. Brasilia: Ministério da Saúde; 2013 [citado el 15 de marzo 2017]. Disponible en: http://www.sierj.org.br/ artigos/htlv_manual_final_pdf_25082.pdf

21. Instituto Nacional de Salud. [Internet] ¿Cuánto conoces del virus HTLV-1? ¡No evitar su contagio vertical es condenable! Post de opinión técnica INSteractua. [Citado el 14 de septiembre del 2016]. Disponible en: http://insteractua.ins.gob. pe/2016/09/cuanto-conoces-del-virushtlv-1-no_14.html

Correspondencia: Soledad Elena Romero Ruiz Dirección: Defensores del Morro 2268. Chorrillos, Perú

Teléfono: (+51) 996302425, (+51) 7480000 anexo 1544/1427

Correo electrónico:soledadromeror@yahoo.com

\title{
Ahora nuestra revista incluye:
}

\author{
$\checkmark$ Publicación anticipada \\ $\checkmark$ Compartiendo publicaciones científicas con el ciudadano \\ $\checkmark$ Videos de presentaciones conjuntas del Instituto Nacional de \\ Salud y la Academia Nacional de Medicina \\ Galería fotográfica y videos
}

会 www.rpmesp.ins.gob.pe

MINISTERIO DE SALUD

Instituto Nacional de Salud

Síguenos en: 